EPIDEMIOLOGICAL REVIEW

\title{
Risk of HIV/AIDS in China: subpopulations of special importance
}

\section{Z H Qian, S H Vermund, N Wang}

Sex Transm Infect 2005;81:442-447. doi: 10.1136/sti.2004.014258

See end of article for authors' affiliations .....................

Correspondence to: Dr Sten H Vermund, Department of Epidemiology, University of Alabama at Birmingham, 1665 University Blvd (Ryals 443A), Birmingham, AL 35294-2200, USA; shvermund@aol.com

Accepted for publication 16 March 2005
Objective: To describe the HIV/AIDS epidemic in mainland China.
Methods: We review the magnitude of the HIV/AIDS epidemic

\begin{abstract}
Methods: We review the magnitude of the HIV/AIDS epidemic and the social characteristics and geographic distribution of at-risk groups in China based on published literature and unpublished official data.

Results: Injection drug use has been the dominant route for HIV infection in China, and will continue to be a major risk factor with increasing numbers of new drug users and needle sharing. Commercial plasma donation with unhygienic re-infusion of red blood cells was common in rural communities in the early 1990s. While this is unlikely to constitute a major factor for future HIV spread, those already infected represent a formidable treatment challenge. Huge seasonal work migration facilitates disease spread across regions. Many homosexual men have unprotected sex with men, women, or both, and may contract or spread HIV. Though commercial sex workers have contributed to a small proportion of the reported epidemic thus far, flourishing commercial sex is of growing concern and may have a bridging role in transmitting HIV from core groups to the general population.

Conclusion: Increasing numbers of sex workers and drug users, internal migration, high risk behaviours, and low condom use suggest a future upward trend for HIV/AIDS and underscore the urgency of scaling up interventions in China.
\end{abstract}

S ince the first AIDS case was diagnosed in 1985, mainland China (excluding Hong Kong, Macao, and Taiwan) has reported 62159 HIV/AIDS cases cumulatively by the end of 2003. The actual number was estimated by the Ministry of Health $(\mathrm{MOH})$ to be nearly one million. As the world's most populous country, China has a low overall HIV prevalence, with nearly $0.1 \%$ infected in the general population (2002). ${ }^{\prime}$ However, the HIV/AIDS epidemic in China is facing a potential explosion; the rise in reported HIV/ AIDS cases was about 30\% per year in the 1998 to 2002 period, with a 54\% rise from 2002 to 2003 alone. UNAIDS warned that China could have 10 million infections and 260000 orphans as a result of AIDS by 2010 if effective intervention measures were not taken. ${ }^{1}$

The HIV/AIDS epidemic in China is largely concentrated in selected areas and population subgroups. Among 31 provinces, autonomous regions, or municipalities, Xinjiang and Yunnan have highest prevalence rates of cumulative reported cases, within the range of 30-45 per 100000 people; Guangxi, Beijing, and Henan are within the range of 10-30 per 100000 (fig 1). HIV infection is primarily attributable to injection drug use (IDU) in the southern (Yunnan, Guangxi, Guangdong), central western (Sichuan, Chongqing, Guizhou), and north western (Xinjiang) regions. In central eastern China, illegal commercial blood collection is primarily responsible for infections in Henan, Anhui, and Hubei. Commercial sex is a major contributor in coastal provinces such as Fujian. Migrant populations from higher risk areas accounts for most cases in Beijing and Shanghai. ${ }^{2}$

We searched English and Chinese language literature via Medline and the China National Knowledge Infrastructure, and reviewed unpublished official data including national HIV/AIDS case reports and sentinel surveillance data. Over 250 papers and reports were reviewed. Key databases included: (1) Chinese Journal of Epidemiology (Zhonghua Liu Xing Bing Xue Za Zhi); (2) National HIV/AIDS case reports
1995-2003; and (3) National HIV sentinel surveillance data 1995-2003.

\section{INJECTION DRUG USERS (IDUs)}

Opium use was popular from late Qing Dynasty (1644-1911 $\mathrm{AD})$ to the founding of new China in 1949, and was almost eradicated after the early 1950s. Drug use re-emerged in the late 1980s, increasing from 70000 registered drug users in 1990 to one million by 2002 (table 1). ${ }^{3}$ China's south western border with the "Golden Triangle" region of South East Asia including Burma (Myanmar), Laos, and parts of Thailand is proximate to one of the major heroin producing areas in the world. ${ }^{3}$ Three drug trafficking routes enter China, two through the Yunnan province from Burma and one into the Guangxi province from Vietnam. These drug trafficking routes then run across several provinces in southwestern, southern, and northwestern China, including Yunnan, Guangxi, Guizhou, Guangdong, Sichuan, and Xinjiang. ${ }^{4}$ Along these routes and beyond, some drug smugglers and local residents have become drug users. The major drugs of choice are heroin and opium; the abuse of amphetamine-type stimulants (ATS) and MDMA (ecstasy) has recently become popular in growing urban areas. ${ }^{5}$

National behavioural surveillance data suggest that injection is an increasingly common route for illicit drug use as a cost effective way of experiencing the effects of the drug, compared to non-injection. ${ }^{6}$ The average prevalence of IDU among drug users increased from 35\% in April 1995 to $61 \%$ in April 2003. ${ }^{7}$ Among IDUs, about $45 \%$ share needles. ${ }^{7}$

Abbreviations: ARV, antiretroviral; ATS, amphetamine-type stimulants; CDC, Center for Disease Prevention and Control of China; CSW, commercial sex worker; FPD, former commercial plasma donor; IDU, injection drug use; $\mathrm{MOH}$, Ministry of Health; MSM, men who have sex with men; MTCT, mother to child transmission; RBC, red blood cells; STD, sexually transmitted diseases; VCT, voluntary counselling and testing 


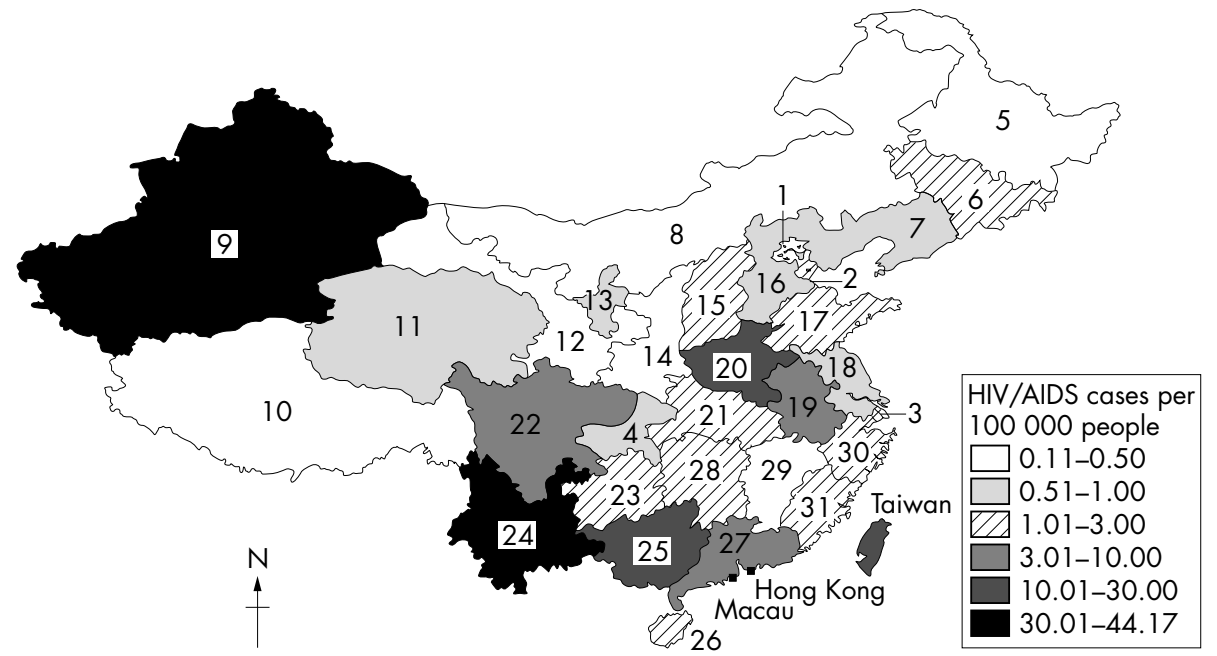

Figure 1 Cumulative reported HIV/AIDS cases in China per 100000 people by region, 1985-2003. Numerators are cumulative cases: denominators are population from the fifth national population census in 2000. 1, Beijing; 2, Tianiin; 3, Shanghai; 4, Chongqing; 5, Heilongiiang; 6 , Jilin; 7, Liaoning; 8, Inner Mongolia; 9, Xinjiang; 10, Xizang (Tibet); 11, Qinghai; 12, Gansu; 13, Ningxia; 14, Shaanxi; 15, Shanxi; 16, Hebei; 17, Shandong; 18, Jiangsu; 19, Anhui; 20, Henan; 21, Hubei; 22, Sichuan; 23, Guizhou; 24, Yunnan; 25, Guangxi; 26, Hainan; 27, Guangdong; 28, Hunan; 29, Jiangxi; 30, Zhejiang; 31, Fujian; Hong Kong, 31.68/100 000 people; Macao, 64.23/100 000 people. Area 1 (Beijing) has same prevalence as areas 20 and $25(10.01-30.00 / 100000)$.

The relation between drug trafficking, drug use, needle sharing, and HIV spread has been well documented in China. $^{8}{ }^{9}$ HIV infection among IDUs began around 1988 in Thailand and Burma. ${ }^{11}$ Analysis of HIV virus subtypes suggests spread from the "Golden Triangle" region to Yunnan Province, ${ }^{412}$ and then further to other parts of China along the drug trafficking routes. ${ }^{4{ }^{12-14}}$ The first HIV outbreak in China was reported in 1989 among IDUs in Ruili city in Yunnan province, bordering Burma. ${ }^{8}$ By 1995, 12 of the 17 prefectures in Yunnan reported HIV infection. ${ }^{15}$ By 1999, the average prevalence of HIV infection among IDUs from sentinel surveys was $27.8 \%{ }^{16}$ The HIV epidemic in Guangxi (east of Yunnan) began in 1989 and accelerated markedly in the years since 1996; more than 500 new cases were reported each year after $1998 .{ }^{17}$ By 2000, 88\% of cumulative HIV/AIDS case reports were the result of IDU. ${ }^{17}$ In Guangdong, HIV began to spread among IDUs in 1997; during 1986-96, 1.4\% of locally reported HIV/AIDS cases were local resident IDUs, but this proportion increased to $73.3 \%$ of case reports in 1999. ${ }^{18}{ }^{19}$ In Xinjiang, HIV prevalence among IDUs increased from $0 \%$ in 1995 to $28.8 \%$ in 1998 in the capital city Urumqi, and was $82.2 \%$ in Yining City in $1998 .{ }^{6}$ High HIV prevalence rates were observed later in selected sentinel sites for IDUs in other provinces-for example,
Jiangxi (14.5\%, 2000 sentinel data), Sichuan (16-20\%, 2002), Guizhou (17-19\%, 2002), and Hunan (15-20\%, 2003). ${ }^{7}$

Although the proportion of reported HIV/AIDS cases attributable to IDU decreased from 71\% during 1985-2000 to $50 \%$ in $2002,{ }^{2}$ HIV prevalence among IDUs increased. In 1995, only one out of eight national sentinel sites for IDUs detected HIV infections, while in 2002, 29 out of 36 sentinel sites did; the average prevalence rates among drug users increased from $0.04 \%$ in 1995 to $5.9 \%$ in 2002 (table 2). ${ }^{70}$

\section{FORMER PLASMA DONORS (FPDs)}

In general, people in China are reluctant to donate blood, as they believe that the loss of blood is unhealthy. In 1996, only $11 \%$ of blood for clinical use was collected from volunteer donors nationwide, although this proportion increased to $67 \%$ in 2000 as a result of vigorous efforts by the government to motivate volunteer donors. ${ }^{21}$ More than $90 \%$ of whole blood donations collected in China are only in $200 \mathrm{ml}$ volumes, in contrast with the Western tradition of 400$500 \mathrm{ml}$ per donation..$^{21}$ Endemic hepatitis also limits voluntary blood donation from a large proportion of the general population because the blood is discarded when screened and found to be positive for hepatitis $\mathrm{B}$ surface antigen or hepatitis $\mathrm{C}$ antibody. A shortage of blood products in China

Table 1 Subgroup populations at higher risk of HIV/AIDS in China

\begin{tabular}{|c|c|c|c|c|}
\hline Population & $\begin{array}{l}\text { Registered/estimated } \\
\text { number (million) }\end{array}$ & $\begin{array}{l}\text { Reported percentage of } \\
\text { HIV/AIDS cases, 1985- } \\
2003+(n=62159)\end{array}$ & $\begin{array}{l}\text { Estimated percentage of } \\
\text { people living with HIV/ } \\
\text { AIDS, } 2003 \ddagger(n=840000)\end{array}$ & $\begin{array}{l}\text { Average HIV } \\
\text { prevalence (range) } \\
\text { (\%) }\end{array}$ \\
\hline Injection drug users & $1.0 / 3.5 \S$ & 51.2 & 43.9 & $7.0(0-94.0) \S$ \\
\hline Former plasma donors & NA & 21.0 & 24.1 & NA $(0.2-56.1)$ \\
\hline Commercial sex workers & $0.4 \oplus / 3.5^{* *}$ & $7.3^{*}$ & $19.8^{*}$ & $1.0(0-11.3) \S$ \\
\hline Men who have sex with men & NA/8.0†† & 0.2 & 11.1 & NA $(0-3.1)$ \\
\hline Others & NA & 20.3 & 1.1 & \\
\hline Total & NA & 100.0 & 100.0 & $0.1(0.1-0.2) \pm \ddagger$ \\
\hline
\end{tabular}

NA, data not available.

*Including their clients and other people infected via heterosexual transmission.

tMinistry of Health of China. ĐJoint assessment by State Council AIDS Working Committee Office and UN Theme Group on HIV/AIDS in China, 2004. §National Drug Abuse Surveillance Center, 2002. §Ministry of Health of China. "Public security report in 1996. **UNAIDS China (1997): China responds to AIDS: HIV/ AIDS situation and needs assessment report. ††Zhang and Ma. \$†Among general population age 15-49 years (end 2003), estimate from UNAIDS: 2004 Report on the global AIDS epidemic. 
Table 2 National sentinel surveillance of HIV/AIDS among selected populations in China, 1995-2002

\begin{tabular}{|c|c|c|c|}
\hline & October 1995 & October 1998 & October 2002 \\
\hline Sites with $>1$ positive HIV test/surveillance sites & $1 / 8$ & $11 / 19$ & $29 / 36$ \\
\hline Positive people/people tested (\%) & $1 / 2652(0.04)$ & $285 / 5536(5.2)$ & $570 / 9713(5.9)$ \\
\hline Prevalence at sites (per 100 people) & & & \\
\hline Lowest/median/highest & $0 / 0 / 0.25$ & $0 / 0.3 / 82.2$ & $0 / 2.5 / 80.0$ \\
\hline \multicolumn{4}{|l|}{ Among commercial sex workers } \\
\hline Sites with $>1$ positive HIV test/surveillance sites & $1 / 12$ & $4 / 21$ & $4 / 31$ \\
\hline Positive people/people tested (\%) & $1 / 3160(0.03)$ & $29 / 5052(0.57)$ & $103 / 7507$ (1.37) \\
\hline Prevalence at sites (per 100 people) & & & \\
\hline Lowest/median/highest & $0 / 0 / 0.3$ & $0 / 0 / 4.5$ & $0 / 0 / 15.9$ \\
\hline \multicolumn{4}{|l|}{ Among STD patients } \\
\hline Sites with $>1$ positive HIV test/surveillance sites & $1 / 15$ & $5 / 35$ & $16 / 56$ \\
\hline Positive people/people tested (\%) & $1 / 4734(0.02)$ & $8 / 10441(0.08)$ & $26 / 10070(0.26)$ \\
\hline Prevalence at sites (per 100 people) & & & \\
\hline Lowest/median/highest & 0/0/0.3 & 0/0/0.7 & $0 / 0 / 2.5$ \\
\hline
\end{tabular}

led to a large market for illegal commercial plasma/blood collections in the 1980s and early 1990s. Hundreds of commercial plasma collection centres were established in counties, townships, and villages in central eastern China. The paid donors were generally farmers from poorer areas who sold plasma or blood to augment their incomes. ${ }^{22}{ }^{23}$

Plasma donation was much more popular than whole blood donation for three reasons: (1) increased commercial demand for plasma; (2) increased willingness to donate when red blood cells (RBC) were re-infused; (3) repeat donations could be solicited in a short time period when anaemia was reduced with RBC re-infusion. Typically, peripheral blood was drawn from several people at the same time. Donations sharing the same blood type were mixed together in a container and the plasma was extracted. RBCs were re-infused with normal saline solution to the donors. Such procedures, along with the reuse of needles and unsterilised equipment, gave endemic blood borne infections an easy route to spread rapidly through the local donor population. $^{22} 23$

Blood screening for HIV for all donors has been required by law in large cities since 1993, but local blood banking or hospital officials often omitted HIV testing both for financial reasons and because they believed they did not have an HIV problem. Since around 1995, the problem of HIV spread among commercial plasma donors began to become apparent. ${ }^{24}{ }^{25}$ The Chinese government took strong legal action to prevent further spread of HIV infections by closing commercial plasma collection centres and issuing new regulations for blood/plasma donation. In 1998, the "Law of blood donation" became effective nationwide, encouraging voluntary donation and requiring HIV screening for all blood donations. Although it was believed that illicit commercial blood/plasma collection has been reduced substantially since 1996, the practice has been occasionally reported in the mass media and it has not been completely eradicated. ${ }^{26}$

There are no official data on the number of commercial blood donors given the illegality of the practice. However, several provinces in central and eastern China, such as Henan, Hubei, Anhui, Shanxi, Hebei, and Shangdong, were believed to have an especially large number of blood donors..$^{24-31}$ By 2003, 21.0\% of cumulatively reported HIV/ AIDS cases in China were attributable to these flawed blood collection methods (table 1).

HIV/AIDS prevalence rates varying from $0.2 \%$ to $56.1 \%$ among paid blood donors have been reported in village surveys where commercial blood banking was documented. ${ }^{29}{ }^{32-34}$ Plasma/blood donation was the strongest predictor of HIV infection in these communities; in one study, $17.0 \%$ prevalence was observed among donors, compared to $0.2 \%$ among non-donors. ${ }^{34}$ Donors aged 30-49 years had nearly twice the risk of other age groups. ${ }^{22}$ Only selected types of blood banks were likely to be responsible for the HIV epidemic among former plasma donors-namely, private or local county government blood banks; the district government and military blood banks were not associated with HIV risk in one study. ${ }^{35}$ Plasma donors had a higher prevalence rate $(25.9 \%)$ than those who donated whole blood $(2.6 \%){ }^{35}$ Donors who donated blood $\geqslant 10$ times per year had a higher prevalence rate $(13.5 \%)$ than those who donated $<10$ times a year $(2.8 \%))^{28}$ The prevalence rates for blood donors were $18.3 \%$ if they donated before $1995,7.7 \%$ if they donated beginning in 1995-6, and $1.4 \%$ if their donation began after $1996 .^{28}$ While it is plausible that these observations are generalisable, they are derived from relatively geographically limited surveys within a vast country.

\section{COMMERCIAL SEX WORKERS (CSWS) AND THEIR CLIENTS}

Prostitution was very common in large trading cities of China in the late 19th century and early 20th century. ${ }^{36}$ It was abolished by 1955 after a national campaign against prostitution and venereal diseases based on changing social mores, closing brothels, and educating and training sex workers for other employment. ${ }^{37}$ Since adopting a free market economy and an open door policy in 1978, China has experienced rapid economic growth, far more in coastal areas and big cities than inland rural areas. Mass migration of rural inland people to coastal cities for job opportunities, widening income gaps, increased business and tourism travel, and more tolerant sexual attitudes have led to widespread commercial sex. The number of sex workers identified by the public security department increased from 25000 in 1986 to 250000 in 1992, and to 420000 in $1996 .{ }^{38}$ The actual number involving in commercial sex is estimated to be 3-4 million people. ${ }^{39}$ Among Chinese men aged 2064 years, $6.4 \%$ have ever engaged in commercial sex at least once during their lives according to a nationwide population based probability survey in $2000 .{ }^{40}$ Condom use in commercial sex is not widespread. According to national behavioural sentinel surveillance data, the median proportion who report always using condoms showed a slowly increasing trend from $13 \%$ in 1995 to $20 \%$ in 2002 . $^{7}$

Much remains to be learnt about CSW in China. Brothels are a far less common phenomenon than in nearby Asian countries. ${ }^{41}$ Transient sex work is common, such that girls or young women will work in "hairdressing salons," "song" bars, bathing centres, hotel bars, dance halls, or from the 
street for a relatively limited time (a few months to a few years). Their goal is to save a "nest egg" to start a small business or help financially troubled parents. ${ }^{42}{ }^{43}$ To maintain relative anonymity, it is common for CSWs to work away from their home towns. Other major motivations to enter into prostitution have included negative sexual or love experiences and, in a small minority, self reported enjoyment of sex work. ${ }^{43}{ }^{44}$ While a majority of women involved in commercial sex are thought to be of rural origin, women laid off from state owned factories and even women who are fully employed are represented among CSWs. These women may work part-time at night and weekends to make extra income. Given the wide variety of sex work, it is hard to generalise their HIV related behaviours. Male prostitution is said to exist but it is rarely seen. The dynamism of modern China suggests the need for ongoing behavioural surveillance to track risk behaviours and trends in CSW.

Along with the growth of commercial sex and continued low rate of condom use, the incidence rates of sexually transmitted diseases (STDs) have increased sharply since the 1980s. Among eight reportable STDs in the whole country, only 50 cases were reported in 1980, 160000 in 1990, and 850000 in 2000. ${ }^{45}$ Many Chinese physicians had virtually no clinical experience with STDs before the 1990s. HIV prevalence rates among STD patients and CSWs show upward trends, and sentinel data in STD clinics have documented this association. Average prevalence among STD clients and CSWs increased from $0.02 \%$ and $0.03 \%$ in 1995, to $0.08 \%$ and $0.57 \%$ in 1998 , and further to $0.26 \%$ and $1.37 \%$ in 2002 , respectively (table 2). ${ }^{720}$ While these HIV prevalence rates are not high by global standards, the upward trend is worrisome. Through 2003, heterosexual transmission accounted for $7.3 \%$ of cumulative reported HIV/AIDS cases in China (table 1).

\section{OTHER SUBPOPULATIONS AT RISK Migrant people}

China has 100-120 million people who travel away from their homes for work each year. ${ }^{47}$ Migrant women of rural origin often lack good education and job skills, and may have limited opportunities to earn money; an increasing number of young women are recruited into sex work. ${ }^{47}$ Migrants are largely young and sexually active; migrant males are likely to become clients of commercial sex workers when far from home and with increased disposable income. Migrants present special challenges for HIV/STD prevention because of these commercial sex links, earlier frequency of commercial plasma/blood donation, and a higher prevalence of drug and alcohol use. Migrants may spread HIV and STDs between rural and urban areas as well as from HIV concentrated regions to low prevalence regions. A convenience sampling of migrants in Beijing and Shanghai showed that 47\% (85/180) of the employment seekers reported engaging in extramarital sex since leaving their place of origin, higher than restaurant workers $(16 \%, 5 / 32)$ and peddlers $(14 \%, 22 / 192)$; migrant employment seekers also had high prevalence of selling blood or plasma and drug use (12\% and $9 \%){ }^{49}$ Migrant blood/ plasma donors were found to have higher HIV prevalence than non-migrants in Hubei province. ${ }^{30}$

\section{Men having sex with men (MSM)}

One estimate suggests that there are up to eight million MSM in China. ${ }^{47}$ While homosexual activities are not illegal in China, neither are they socially acceptable. Homosexual or bisexual men are still under social pressure to hide their sexual orientation and to be married. ${ }^{50}{ }^{51}$ This often makes it very difficult to provide education to MSM about safer sex practices and to conduct research. Married MSM may acquire HIV from their high risk male sexual partners and transmit to their low risk wives. A convenience sample of 481 homosexual men in Beijing showed 3.1\% to be HIV positive, and $49 \%$ of participants reported unprotected anal intercourse in the previous 6 months. ${ }^{51}$ A molecular epidemiological study found a predominance of subtype B among Beijing MSM, suggesting an origin from the United States, Europe, Australia, or selected Asian cities. ${ }^{52}$

\section{Blood recipients}

Since 1995, China has developed strict guidelines to demand that all blood be screened for HIV and other blood borne diseases before clinical use. However, there are still HIV cases reported through blood transfusion in rural areas. Several reasons exist for iatrogenic transmission, including failure to screen blood and blood products, shortages and/or reuse of injection equipment, unnecessary injection or transfusion, ineffective sterilisation of medical equipment, and lack of training in universal precautions.

\section{Children born to HIV infected mothers}

Although pregnant women and children have been at low risk to date, as the HIV epidemic further spreads, an increasing number of low risk women will be infected and mother to child transmission (MTCT) will increase. Sentinel HIV data in the higher prevalence Yunnan province showed little change among pregnant women from $0.15 \%$ in $1991-8$ to $0.2 \%$ in $1998-2001,{ }^{53-55}$ but it increased to $0.37 \%$ in 2003 $(\mathrm{MOH} / \mathrm{CDC})$. The MTCT rate was $38 \%$ in one Chinese study, reflecting cumulative antenatal, intrapartum and breastfeeding risk in the absence of antiretroviral intervention. ${ }^{335}$ MTCT is probably increasing where outbreaks have occurred among needle sharing drug users and paid plasma/blood donors in the 1990s, but these transmission events may be under-reported. Through 2002, only 96 cumulative perinatal cases had been reported nationwide, though 73 of these cases (76\%) were reported in 2001 and $2002 .^{2}$

\section{FUTURE PERSPECTIVES}

It is difficult to predict future trends for HIV/AIDS based on the past epidemic in China. Cumulative reported cases do not reflect recent incident HIV infections, but represent cumulative transmission patterns over the past two decades. For example, many plasma donors were infected in the 1990s but they were reported with HIV or AIDS only recently. Furthermore, the average $30 \%$ rise in HIV/AIDS per year during 1998-2002 and the 54\% rise in 2003, compared to 2002, may be the result of improved screening and surveillance efforts, and does not reflect the precise magnitude of a rising trend.

IDU is the dominant transmission route in the recognised epidemic so far. The number of HIV infections among drug users will continue to rise because of their increasing number and high levels of injection and needle sharing. The declining proportion of IDU cases in the cumulative reported cases, from $73 \%$ in 1994 to $64 \%$ in 2002 , reflects more the expansion of HIV rather than prevention successes among IDUs. Many IDUs are rural farmers who are less mobile, less financially affluent, and live in the relative remote areas of Yunnan, Xinjiang, or Guangxi provinces. If drug use itself expands, especially if more urban residents become IDUs, the risk of transmitting HIV among IDUs themselves and to general population will increase without risk reduction and drug prevention/treatment intervention.

Commercial plasma donation activities are not now a major risk for new infections. However, infected former donors are developing clinical AIDS and represent a huge clinical care challenge. In Shanxi province where FPDs account for $76 \%$ of all infections, AIDS case reports are rising much faster than HIV non-AIDS cases, despite expanded 
voluntary counselling and testing (VCT) programmes in recent years. ${ }^{57}$ Providing antiretroviral (ARV) therapy and care in these rural communities present logistical, financial, and staffing challenges, China lacks trained physicians and nurses to provide ARV regimens and medical facilities to monitor ARV therapy, especially in rural communities hit hard by HIV. The historical "barefoot doctor" system is no longer a free service, nor are these now upgraded allied health professionals yet qualified to provide ARV based care.

Several factors may influence future HIV trends among MSM. Homosexual activity is not socially acceptable at present; many, if not most, Chinese would consider MSM an abnormality, more stigmatised than female commercial sex work. Recognised MSM tend to be more educated, live in large cities, and have a wide social network, ${ }^{50}{ }^{51}$ which potentially increases their likelihood of adopting HIV prevention methods through peer education mechanisms. On the other hand, stigma for male homosexual activities drive MSM underground and hinder preventive and educational programmes. Of 481 participants in Beijing, 49\% reported unprotected anal intercourse with men, and $22 \%$ reported unprotected anal or vaginal intercourse with women in past 6 months. ${ }^{51}$ The wide social network of many urban MSM may put them at increasing risk as China continues its social and sexual liberalisation. However, based on limited available data, MSM are not likely to account for a large part of the total Chinese HIV/AIDS epidemic in the near future.

Heterosexual transmission is becoming a growing concern because of widespread commercial sex and the low rate of condom use in China. Thailand experienced "five waves" of an HIV/AIDS epidemic: from injection drug users, to female sex workers, to STD patients, to the wives and girlfriends of STD patients, and to their infants. Men who frequented CSWs were the key group bridging HIV transmission from the "core population" to the general population. ${ }^{58}$ In China, sex workers and their male clients may become a similar bridge. Furthermore, some female sex workers are also drug users, often using CSW to support their drug habits. ${ }^{44} 59$ This subgroup with both commercial sex and drug use risk is of highest public health importance.

Our review documents a growing HIV/AIDS epidemic in China. The window for China to shun a generalised epidemic is narrowing. Interventions targeting at-risk subgroups should be accompanied by mass media campaigns as a cost effective way to increase the awareness of prevention among the general population. Considering China's huge population size and wide geographic area, the extensive reach of the centralised Chinese media should be exploited. The central Chinese government has begun to take a pragmatic attitude towards HIV prevention and control efforts. Pilot projects of needle exchange and methadone maintenance treatment are being implemented; the China Cares Project was initiated in 2003 in 51 county level communities with a high proportion of former plasma donors or drug users. The China Care Project provides HIV counselling and testing, ARV therapy and care, and prevention of MTCT. However, many local government officials remain unconvinced; only with commitment and support from both central government and local governments is it possible to scale up interventions from their current pilot levels. We hope that this report can be updated in 2-3 years to describe the successes of the Chinese efforts to reduce HIV transmission and expand HIV care and treatment.

\section{ACKNOWLEDGEMENTS}

This work was supported by UAB/Fogarty AIDS International Training Fellowship (US NIH grant No 5D43TW01035-05) and China Integrated Programs for Research on AIDS (NIH/NIAID grant No U19AI51915).

\section{Key messages}

- This paper provides a critical review of the magnitudes of the HIV/AIDS epidemic and the social characteristics and geographic distribution of at-risk groups in China based on published literature and unpublished official data

- Subgroups at higher HIV risk are shifting from injection drug users and former commercial plasma donors to commercial sex workers and their clients, and men who have sex with men

- Those already infected people, especially infected rural residents, represent a significant treatment and care challenge in some heavily affected areas

- The growing epidemic trend underscores the urgency of scaling up interventions among at-risk subgroup populations as well as the need to educate the general population

\section{CONTRIBUTORS}

HZQ initiated the study, obtained and analysed the data, and drafted the manuscript; SHV interpreted the data, and co-wrote the manuscript; NW obtained and analysed the data, and edited the manuscript.

\section{Authors' affiliations}

Z H Qian, S H Vermund, Department of Epidemiology, School of Public Health, University of Alabama at Birmingham, AL, USA

Z H Qian, N Wang, National Center for AIDS/STD Control and Prevention, Chinese Center for Disease Control and Prevention, Beijing, China

\section{REFERENCES}

1 UNAIDS. National response brief-China, Available at: www.unaids.org/ nationalresponse/result.asp, accessed 16 February, 2005.

2 Ministry of Health of China. National HIV/AIDS case report 2003.

3 Zhao CZ, Liu ZM, Zhao D, et al. Drug abuse in China. Ann N Y Acad Sci 2004; 1025:439-45

4 Beyrer C, Razak MH, Lisam K, et al. Overland heroin trafficking routes and HIV-1 spread in south and south-east Asia. AIDS 2000;14:75-83.

5 Kulsudjarit K. Drug problem in southeast and southwest Asia. Ann N Y Acad Sci 2004; 1025:446-57.

6 Ming ZQ, Liang SL, Yap L, et al. Qualitative study of drug using and sexual behaviors of drug users in Guangxi. Zhonghua Liu Xing Bing Xue Za Zhi 2002;23:111-13.

7 Ministry of Health of China. National HIV sentinel surveillance data, 19952003.

8 Ma Y, Li ZZ, Zhang KX, et al. HIV was first discovered among IDUs in China. Zhonghua Liu Xing Bing Xue Za Zhi 1990;11:184-5.

9 Zheng $X W$, Tian $\mathrm{C}$, Choi $\mathrm{KH}$, et al. Injecting drug use and HIV infection in southwest China. AIDS 1994;8:141-7.

10 Nelson KE. The epidemiology of HIV infection among injecting drug users and other risk populations in Thailand. AIDS 1994:8:1499-500.

11 Htoon MT, Lwin HH, San KO, et al. HIV/AIDS in Myanmar. AIDS 1994;8(Suppl 2): 105-9.

12 Piyasirisilp S, McCutchan FE, Carr JK, et al. A recent outbreak of human immunodeficiency virus type 1 infection in southern China was initiated by two highly homogeneous, geographically separated strains, circulating recombinant. J Virol 2000;74:11286-95.

13 Yu XF, Liu W, Chen J, et al. Rapid dissemination of a novel B/C recombinant HIV-1 among injection drug users in southern China. [letter] AIDS $2001 ; 15: 523-38$

14 Qing GM, Shao YM, Liu G, et al. Genetic sequence and subtypes of HIV-1 in Sichuan Province. Zhonghua Liu Xing Bing Xue Za Zhi 1998;19:39-42.

15 Chen HH, Zhang JP, Kou JD, et al. The trend of HIV spread across the whole province of Yunnan - surveillance report of Yunnan 1995. Zhongguo Xing Bing Ai Zi Bing Fang Zhi 1996;2:54-7.

16 Chen HH, Zhang JP, Pan SF, et al. Analysis and prediction on the trends of HIV infection epidemic in Yunnan province. Zhongguo Xing Bing Ai Zi Bing Fang Zhi 2000;6:257-60

17 Liu W, Chen J, Li Z, et al. Analysis of HIV epidemic trends in Guangxi, China. Guangxi Yu Fang Yi Xue 2001;7:257-9.

18 Lin $\mathrm{P}, \mathrm{Xu} \mathrm{RH}$, Zeng $\mathrm{CH}$, et al. Trend and characteristics of HIV/AIDS epidemic in Guangdong Province, 1986-1999. Zhonghua Liu Xing Bing Xue Za Zhi $2001 ; 22: 194-7$. 
19 Lin M, Lin P, Li H, et al. Epidemiological study on HIV/AIDS in Guangdong Province. Zhongguo Xing Bing Ai Zi Bing Fang Zhi 2001;7:11-13.

20 Ministry of Health (MOH), National Center for AIDS Prevention and Contro (NCAIDS) and Collaboration Group for National HIV Sentinel Surveillance Program. Set up of national sentinel surveillance of HIV infection in China and its report in 1995. Zhongguo Xing Bing Ai Zi Bing Fang Zhi 1996;2:193-7.

21 Shan H, Wang JX, Ren FR, et al. Blood banking in China. Lancet 2002;360:1770-5.

22 Wu ZY, Rou KM, Detels R. Prevalence of HIV infection among former commercial plasma donors in rural eastern China. Health Policy Plann $2001 ; 16: 41-6$.

23 Beach MV. "Blood heads" and AIDS haunt China's countryside. Lancet 2001;357:49.

24 Wu ZY, Liu ZY, Detels R. HIV-1 infection in commercial plasma donors in China [letter]. Lancet 1995;346:61-2.

25 Zheng XW. Stop the spread of HIV among drug users and blood donors in China [editorial]. Zhonghua Liu Xing Bing Xue Za Zhi 2000;21:6.

26 Writer's Digest, "Opening the black cover of illicit drug sale." 22 November, 2002:p7.

27 Su HC. Blood-borne diseases in plasma samples in Henan Province. Ji Bing Jian Ce 1997;12:251-3.

28 Yan JY, Zheng XW, Zhang XF, et al. The survey of prevalence of HIV infection among paid blood donors in one county of China. Zhonghua Liu Xing Bing Xue Za Zhi 2000;21:10-12.

29 Liu SZ, Zheng XW, Fu JH, et al. HIV prevalence and subtypes among paid blood donors in Shandong and Hubei provinces, China. Zhongguo Yu Fang Yi Xue Za Zhi $2001 ; 2: 8-11$.

30 Liu ZF, Mei ZQ, Zheng XW, et al. Investigation of HIV infection among plasma donors in three illegal plasma collection places in central China. Zhonghua Liu Xing Bing Xue Za Zhi 2000;21:466-7.

31 Liu SZ, Fu JH, Su SL, et al. Survey of HIV infection among blood donors in a rural area in Shangdong Province. Shi Yong Yu Fang Yi Xue 2000;7:430-1.

32 Chen $\mathrm{X}, \mathrm{He} J \mathrm{M}, \mathrm{Wu} \mathrm{HQ}$, et al. A seroepidemiolgic and behavioral study of $\mathrm{HIV}, \mathrm{HCV}, \mathrm{HBV}$ and syphilis infection among commercial blood donors. Shi Yong Yu Fan Yi Xue 1999;6:174-6

33 Zhuang K, Gui XE, Su B, et al. High prevalence of HIV infection among women and their children in Henan Province, China [letter]. J Acquir Immune Defic Syndr 2003;33:649-57.

34 Zheng XW, Wang Z, Xu J, et al. The epidemiological study of HIV infection among paid blood donors in one county of China. Zhonghua Liu Xing Bing Xue Za Zhi 2000;21:253-5.

35 Chen H, Qian X, Cao GH, et al. Study on the seropositive prevalence of human immunodeficiency virus in a village residents living in rural region of central China. Zhonghua Liu Xing Bing Xue Za Zhi 2004;25:317-21.

36 Chu W, Huang $\mathrm{CH}$. Gonorrhea among prostitutes: a survey of the incidence and an attempt at oral sulfadiazine prophylaxis. Chung Hua I Hsue Tsa Chih 1948;66:312-18.

37 Cohen MS, Henderson GE, Aiello P. Successful eradication of sexually transmitted diseases in the People's Republic of China: implications for the 21 st century. J Infect Dis 1996; 174:S223-9.

38 Liao SS, Schensul J, Wolffers I. Sex-related health risks and implications fro interventions with hospitality women in Hainan, China. AIDS Educ Prev 2003;15:109-21.
39 Huang YY, Henderson GE, Pan SM, et al. HIV/AIDS risk among brotherbased female sex workers in China: assessing the terms, content, and knowledge of sex worker. Sex Transm Dis 2004;31:695-700.

40 Pan SM, Parish WL, Wang AL, eds. Zhongguoren de Xing Guangxi yu Xing Xingwei 1999-2000 (Chinese People's Sexual Relationships and Sexual Behavior). Beijing: Social Science Document Publishing House, 2004.

41 World Health Organization Western Pacific Region. Sex work in Asia. Available at www.wpro.who.int/siteserver/knowledge/search/ sex + work+in+Asia $=$ SearchRightasp?ct $=$ ALL\&ql, accessed 16 February, 2005.

42 Pan SM, ed. Cun Zai Yu Huang Miu_Zhong Guo Di Xia Xing Chan Ye Kao Cha. Beijing: Qunyan Publishing House, 2001.

43 Gil VE, Wang MS, Anderson AF, et al. Prostitutes, prostitution and STD/HIV transmission in mainland China. Soc Sci Med 1996;42:141-52.

44 Qian HZ, Zhao PF, Jiang YF, et al. Demographic profile and HIV risk behaviors among female drug users in Shanghai [Abstract 23576]. Presented at the 12th World AIDS Conference, Geneva, 1998.

45 Zhang JY. The past, present and future epidemic of sexually transmitted diseases in China. Zhonghua Liu Xing Bing Xue Za Zhi 1998;19:118-21.

46 Gong XD, Ye SZ, Zhang GC, et al. An epidemiological analysis of sexually transmitted diseases in China in 2000. Zhongguo Xing Bing Ai Zi Bing Fang Zhi 2001;7:131-4.

47 Zhang KL, Ma SJ. Epidemiology of HIV in China [Editorial]. BMJ 2002;324:803-4

48 Liao SS. HIV in China: epidemiology and risk factors. AIDS 1998; 12:S19-S25.

49 Anderson AF, Qingsi Z, Hua X, et al. China's floating population and the potential for HIV transmission: a social-behavioral perspective. AIDS Care 2003; 15:177-95

50 Zhang BC, Liu DC, Li XF, et al. A survey of men who have sex with men: mainland China [letter]. Am J Public Health 2000;90:1949-50.

51 Choi KH, Liu H, Guo YQ, et al. Emerging HIV-1 epidemic in China in men who have sex with men [letter]. Lancet 2003;361:2125-6.

52 Yao J, Zhang FJ, He ZP, et al. Subtypes of HIV infection among homosexuals in Beijing. Zhonghua Liu Xing Bing Xue Za Zhi 2003;24:159.

$53 \mathrm{Li} \mathrm{H}, \mathrm{Mo}$ LH, Liu H, et al. Prevention of HIV transmission from mother to child in Yunnan. Xian Dai Yu Fang Yi Xue 2001 ;28:68-9.

54 Zhang XB, Ma YL, Yu HF, et al. Analysis of HIV/AIDS surveillance data in Yunnan, 2001. Ji Bing Jian Ce 2002;17:327-9.

55 Yuan JH, lonita G, Xu Y, et al. The HIV/AIDS projection in Yunnan. Zhongguo Xing Bing Ai Zi Bing Fang Zhi 2002;8:78-81.

$56 \mathrm{Cao}$ YZ, Li GH, Wang SY, et al. Current situation, crisis and control strategies of HIV-1 mother-to-child transmission in China. Zhongguo Chuan Ran Bing Xue Za Zhi 2002;20:185-8.

57 Qiao XC, Nie XY, Guo XL. Analysis of the epidemic of HIV/AIDS in Shanx province and the strategy for HIV/AIDS prevention and control. Zhongguo Xing Bing Ai Zi Bing Fang Zhi 2004;10:190-2.

58 Morris M, Podhisita C, Wawer MJ, et al. Bridge populations in the spread of HIV/AIDS in Thailand. AIDS 1996;10:1265-71.

59 Zhao PF, Yu H. Study on sexual and drug use behaviors of high risk among sex workers in entertainment establishments in Shanghai. Zhonghua Liu Xing Bing Xue Za Zhi 2001;22:341-3. 


\section{REFERENCES}

1 De Araujo M. East Timor is ripe for HIV/AIDS tragedy. Ministerial statement on HIV. Dili: East Timor Ministry of Health, 5 July, 2002.

2 Menu E, Reynes JM, Muller-Trutwin MC, et al. Predominance of CCR5dependent HIV-1 subtype E isolates in Cambodia. J Acquir Immune Defic Syndr Hum Retrovirol 1999;20:481-7.

3 Ryan CA, Vathiny OV, Gorbach PM, et al. Explosive spread of HIV-1 and sexually transmitted diseases in Cambodia. Lancet 1998;351:1175.

4 Huffam S, Currie BJ, Knibbs P, et al. HIV-1 infection in foreign nationals working in East Timor. Lancet 2002;360:416.

5 Setiawan AD. Laporan Hasil Penelitian Formatif Kelompok Beresiko Tinggi HIV/AIDS di Dili, East Timor 2003. Dili: Family Health International, 2003.

6 Tanujaya FK, Jazan S, Sutrisna A, et al. Sexually transmitted and blood-borne infection prevalence assessment in high-risk populations. a reproductive tract infection prevalence assessment in female sex workers in Jayapura, Medan, Tanjung Pinang, Bitung, Banyuwangi, Semarang, and Palembang, Indonesia. Jakarta: Indonesia Ministry of Health, Family Health International, 2004.

7 Democratic Republic of Timor-Leste. Health profile of the Democratic Republic of Timor-Leste. Dili: World Health Organization, Regional Office for SouthEast Asia, 2002.

8 Monitoring the AIDS Pandemic. AIDS in Asia: face the facts. Bangkok: Monitoring the AIDS Pandemic, 2004.

9 Pisani E, Garnett GP, Grassly NC, et al. Back to basics in HIV prevention: focus on exposure. BMJ 2003;326:1384-7.

10 UNICEF. At-a-glance: Timor Leste, UNICEF, 2004

11 Central Intelligence Agency. The world fact book, East Timor. Washington: CIA, 2004.

\section{CORRECTION}

doi: 10.1136/sti.2004.014258.corr l

In the December issue of the journal there was a mistake in the paper by $\mathrm{H} \mathrm{Z}$ Qian et al (Risk of HIV/AIDS in China: subpopulations of special importance. Sex Transm Infect 2005;81:442-7). The name of the first author was misspelled. The correct spelling is as above. 